\title{
Effects of Platelet Depletion on the Unanesthetized Sheep's Pulmonary Response to Endotoxemia
}

\author{
James R. Snapper, James M. Hinson, Jr., \\ Arlene A. Hutchison, Peter L. Lefferts, \\ Martin L. Ogletree, and Kenneth L. Brigham \\ Pulmonary Circulation Center, Department of Medicine, \\ Vanderbilt University School of Medicine, \\ Nashville, Tennessee 37232
}

bstract. The effect of platelet depletion on the unanesthetized sheep's pulmonary response to endotoxemia was studied in eight unanesthetized sheep. Platelets were depleted with rabbit anti-sheep platelet antibodies (APA). Bolus injections of APA alone caused marked pulmonary hypertension $\left(P_{P A}\right.$ increased from $21 \pm 2$ to $62 \pm 5 \mathrm{~cm} \mathrm{H}_{2} \mathrm{O} \pm \mathrm{SE}$ ) and alterations in lung mechanics (dynamic compliance of the lung $\left[\mathrm{C}_{\mathrm{dyn}}\right] \mathrm{de}-$ creased to $38.5 \pm 4.6 \%$ and resistance to air flow across the lung $\left[R_{L}\right]$ increased to $705 \pm 162 \% \pm S E$ of control), which were attenuated by pretreatment with meclofenamate. It was possible to deplete platelets before endotoxemia through a slow continuous infusion of APA without altering base-line values of the measured variables. Platelet depletion did not significantly attenuate the alterations in pulmonary hemodynamics, lung mechanics, lung fluid and solute exchange, or the normal increase in lung lymph concentrations of thromboxane $B_{2}$ or 6-keto-PGF ${ }_{1 \alpha}$ observed following endotoxemia in the sheep. We conclude that normal circulating platelet counts are not required for the full expression of the sheep's response to endotoxemia.

\section{Introduction}

The experiments described here were designed to test the hypothesis that normal circulating platelet counts are required for the full expression of the sheep's response to endotoxemia. Platelets were depleted with rabbit anti-sheep platelet antibodies

Address correspondence to Dr. Snapper.

Received for publication 21 February 1984 and in revised form 12 July 1984.

J. Clin. Invest.

(C) The American Society for Clinical Investigation, Inc. $0021-9738 / 84 / 11 / 1782 / 10 \quad \$ 1.00$

Volume 74, November 1984, 1782-1791
(APA). ${ }^{1}$ Since the antibodies themselves can cause dramatic changes in pulmonary hemodynamics and lung mechanics, alterations similar to those observed early following endotoxemia (1-3), the effects of APA alone, were also studied.

Endotoxemia has been used, in the unanesthetized sheep, as an animal model of the adult respiratory distress syndrome (ARDS) (1-3). Various interventions such as cyclooxygenase inhibition (1), corticosteroids (4), and granulocyte depletion $(5,6)$ alter one or more aspect of the response to endotoxemia. Platelets are a potentially rich source of agents, such as thromboxane $A_{2}$, which may mediate part of the sheep's response to endotoxemia (7-14). A role for platelets has been proposed in the lung injury observed following hemorrhagic shock (12), glass bead microembolism (11), complement activation (8), oleic acid (13), as well as endotoxemia $(13,14)$, and in ARDS in man (7-14). Experimental evidence from glass bead microembolization (11) and complement activation (8) argues against a pathogenetically important role for platelets in these types of lung injury. The pulmonary sequestration of platelets observed in hemorrhagic shock may be due to decreased pulmonary blood flow (10), while, in oleic acid lung injury, pulmonary entrapment of platelets was unrelated to changes in physiologic dead space, pulmonary vascular resistance, or compliance (13). The authors suggest that pulmonary platelet entrapment may cause endothelial damage (13). Studies with platelet depletion and endotoxin shock in dogs suggest a possible role for platelets only in the early pulmonary hypertension and increased pulmonary vascular resistance observed following endotoxemia (14).

Bolus injections of APA cause marked changes in pulmonary hemodynamics and lung mechanics in the current series of experiments. These changes, like the early alterations ob-

1. Abbreviations used in this paper: $\triangle \mathrm{AaPO}_{2}$, alveolar-to-arterial oxygen difference; APA, anti-platelet antibodies; ARDS, adult respiratory distress syndrome; $C_{d y n}$, dynamic compliance of the lung; $C_{L P}$, lymph protein clearance; $F R C$, functional residual capacity; $P_{\mathrm{PA}}$, pulmonary artery pressure; PG, prostaglandin; PVR, pulmonary vascular resistance; $R_{L}$, resistance to air flow across the lung; $S G_{L}$, specific conductance; $\mathrm{TxB}_{2}$, thromboxane $\mathrm{B}_{2}$. 
served following endotoxemia $(1,15)$, were attenuated by cyclooxygenase inhibition. When platelets were depleted by a slow infusion of APA to minimize changes in lung function, platelet depletion did not attenuate the sheep's response to endotoxemia. Normal circulating platelet counts are not necessary for the full expression of the sheep's response to endotoxemia.

\section{Methods}

\section{Sheep preparation}

Yearling sheep were instrumented as previously described $(1,16)$ Through a left thoracotomy, catheters were placed directly into the left atrium and pulmonary artery. Catheters were passed from the neck into the vena cava and the thoracic aorta. A thermal dilution Swan-Ganz catheter was passed through the external jugular vein into the pulmonary artery for measuring cardiac output using an Edwards model 9520A Thermodilution Cardiac Output Computer (Edwards Laboratory, Santa Ana, CA). Through a right thoracotomy, a silastic catheter was placed in the efferent lymph duct emerging from the caudal mediastinal lymph node. The tail of the caudal mediastinal lymph node was resected below the inferior pulmonary ligaments through a second right-sided thoracotomy. An additional left thoracotomy was performed to disrupt systemic lymph vessels running across the left hemidiaphragm and entering the caudal mediastinal lymph node, causing systemic contamination of the lung lymph (17). A similar disruption was performed on the right hemidiaphragm when the tail of the caudal mediastinal lymph node was resected. At the time of the right thoracotomy, a silastic envelope was placed in the pleural space for the measurement of pleural pressure. This rectangular envelope measured $4 \times 3 \mathrm{~cm}$ and was constructed from silastic sheeting, and a silastic catheter (internal diam, $0.157 \mathrm{~cm}$ ) extended from within the silastic envelope. A tracheostomy was performed and a size 10 Shiley-cuffed tracheostomy tube inserted. Sheep were allowed to recover for several days following surgery.

\section{Lung mechanics}

Awake sheep were studied while standing in a specially constructed whole-body pressure-compensated integrated-flow plethysmograph. The sheep's tracheostomy tube was connected to an external valve via flexible noncollapsible tubing. This permitted the animal to move without interfering with measurements. A loosely fitting sling was placed under the sheep to prevent it from lying while in the plethysmograph. A constant bias flow was used to reduce the effective deadspace of the tubing. Tidal volume $(V)$ was measured by pressure compensating the integrated signal from the plethysmographic pressure transducer. Flow $(\dot{V})$ was obtained by electrically differentiating the volume signal. Airway opening pressure $\left(P_{\mathrm{ao}}\right)$ was measured by a multiple side hole catheter positioned $0.5 \mathrm{~cm}$ past the distal end of the tracheostomy tube. Pleural pressure $\left(P_{\mathrm{pl}}\right)$ was measured directly from the silastic catheter and envelope in the pleural space. Transpulmonary pressure $\left(P_{\mathrm{tp}}\right)$ was the pressure difference between $P_{\mathrm{pl}}$ and $P_{\mathrm{ao}}$. All pressure signals were measured using Validyne pressure transducers and amplification equipment (Validyne Engineering Corp., Northridge, CA). The signals from pressure transducers, catheters, and silastic envelope were tuned to eliminate phasic distortion to $20 \mathrm{~Hz}$. These methods have been described in detail elsewhere $(1,6)$.

Before each set of measurements of lung mechanics, the sheep's lungs were inflated to $40 \mathrm{~cm} \mathrm{H}_{2} \mathrm{O}$ airway opening pressure using the bias flow and an occluded airway. Simultaneous $V / \dot{V}$ and $V / P_{\text {tp }}$ curves were then recorded during spontaneous respiration on a Tektronix dual beam storage oscilloscope and photographed for calculation of dynamic compliance of the lung $\left(\mathrm{C}_{\mathrm{dyn}}\right)$ and resistance to air flow across the lung $\left(\mathrm{R}_{\mathrm{L}}\right)$. $\mathrm{C}_{\mathrm{dyn}}$ was calculated as $V$ divided by $P_{\mathrm{tp}}$ at points of zero flow and expressed in liter per centimeter $\mathrm{H}_{2} \mathrm{O}$ at body temperature pressure standard. $\mathrm{R}_{\mathrm{L}}$ was calculated using the method of von Neergaard and Wirz (18) by dividing $P_{\mathrm{tp}}$ by $\dot{V}$ at midtidal volume and was expressed as centimeters $\mathrm{H}_{2} \mathrm{O}$ per liter per second at body temperature pressure standard. Functional residual capacity (FRC) was measured using the Boyle's law method of DuBois et al. (19). The airway was manually obstructed at end expiration. The sheep continued to make respiratory efforts against the obstruction for one to three breaths and a graph of the change in plethysmographic volume against the change in $P_{\text {ao }}$ was traced on the oscilloscope and photographed for calculation of FRC. Specific conductance, $\mathrm{SG}_{\mathrm{L}}$, was calculated by dividing the reciprocal of resistance to air flow across the lung $\left(R_{\mathrm{L}}\right)$ (conductance) by FRC and expressed as seconds per centimeter $\mathrm{H}_{2} \mathrm{O}$ at body temperature pressure standard.

\section{Thromboxane $B_{2}\left(T x B_{2}\right)$ and prostacyclin metabolites}

$\mathrm{TxB}_{2}$ and 6-keto-prostaglandin $(\mathrm{PG}) \mathrm{F}_{\mathrm{l} \alpha}$ were measured in lung lymph and plasma specimens collected during base line at 30-60, 120-150, and 240-270 min after endotoxemia or after beginning the meclofenamate infusion in the meclofenamate-alone experiments. Analyses were performed by radioimmunoassay employing rabbit anti- $\mathrm{TxB}_{2}$ and anti-6-keto-PGF ${ }_{1 \mathrm{c}}$ antibodies obtained from Dr. J. Bryan Smith (Cardeza Foundation, Philadelphia, PA). The anti- $\mathrm{TxB}_{2}$ antibody cross reacts $<1 \%$ with $\mathrm{PGE}_{2}, \mathrm{PGF}_{2 \alpha}$, and 6-keto-PGF ${ }_{1 \alpha}$, and $<3 \%$ with $\mathrm{PGD}_{2}$ The 6-keto-PGF ${ }_{1 \alpha}$ antibody cross reacts $<3 \%$ with $\mathrm{PGF}_{2 \alpha}$, and $<1 \%$ with $\mathrm{PGE}_{2}, \mathrm{PGD}_{2}$, and $\mathrm{TxB}_{2}$. Authentic prostaglandins and $\mathrm{TxB}_{2}$ were generously supplied by Dr. John Pike (Upjohn Co., Kalamazoo, MI). Radiolabeled $\left[5,6,8,9,11,12,14,15-{ }^{3} \mathrm{H}\right] \mathrm{T} \times \mathrm{B}_{2}$ and $[5,6,8,9,11,12$,$\left.14,15-{ }^{3} \mathrm{H}\right] 6-$ keto-PGF ${ }_{1 \alpha}$ were purchased from New England Nuclear (Boston, MA). Bovine $\gamma$-globulins, Trizma buffer, and ammonium sulfate were purchased from Sigma Chemical Co. (St. Louis, MO).

The radiolabeled ligand $(\simeq 2,000 \mathrm{cpm} /$ tube $)$ was first mixed with bovine $\gamma$-globulins $(10 \mathrm{mg} / \mathrm{ml}$ in Trizma, $\mathrm{pH} 7.4)$. To $100 \mu$ laliquots of this mixture were added $100 \mu \mathrm{l}$ aliquots of sample or appropriate unlabeled standard dilutions. The binding reaction was initiated by addition of $100 \mu$ l of the appropriate antibody diluted to yield $60 \%$ binding of the label. The binding reaction continued for $60 \mathrm{~min}$ at $37^{\circ} \mathrm{C}$ and was terminated by precipitation of the immune complexes with ammonium sulfate at a final concentration of $50 \%$ of saturation. After centrifugation at $2,500 \mathrm{~g}$ at $4^{\circ} \mathrm{C}$ for $10 \mathrm{~min}, 300 \mu \mathrm{l}$ of supernatant were counted in Aquasol (New England Nuclear). Each sample was assayed in duplicate, and duplicate determinations differed by $<10 \%$. The detection limit of both assays was $<20 \% \mathrm{pg}$.

\section{Other variables}

Pulmonary artery pressure $\left(\mathrm{P}_{\mathrm{PA}}\right)$, left atrial pressure $\left(P_{\mathrm{la}}\right)$, and aortic pressure $\left(P_{\mathrm{sa}}\right)$ were continuously monitored using Hewlett Packard Model 1208C pressure transducers (Hewlett Packard Co., Palo Alto, CA). Pulmonary vascular resistance (PVR) was calculated by subtracting $P_{1 \mathrm{a}}$ from $P_{P A}$ and dividing by cardiac output. Lung lymph was collected continuously with flow determined for each 15-min interval and samples of lymph and blood were collected every $0.5 \mathrm{~h}$ for measurement of total proteins. Total protein concentrations in lung lymph and blood plasma were measured by a modified biuret method (20) with an automated system (AutoAnalyzer, Technicon Instruments Corp., Tarrytown, NY). Lymph protein clearance $\left(C_{L P}\right)$ was calculated by 
multiplying the lymph flow by the lymph-to-plasma protein concentration ratio. Arterial blood samples were collected every $0.5 \mathrm{~h}$ anaerobically during steady state base-line conditions and experimental periods and $\mathrm{PO}_{2}, \mathrm{PCO}_{2}$, and $\mathrm{pH}$ were measured using an Instrumentation Laboratories (Lexington, MA) model 513 blood gas analyzer. The alveolar-to-arterial oxygen difference $\left(\triangle \mathrm{AaPO}_{2}\right)$ on room air was calculated using the alveolar gas equation with a fixed respiratory exchange ratio of 0.8 . Lung mechanics were measured every $15 \mathrm{~min}$ except during the first hour following endotoxemia when they were measured every $7.5 \mathrm{~min}$. Leukocyte counts were done every $0.5 \mathrm{~h}$ on an automated system (Coulter Counter Model ZBI, Coulter Electronics, Hialeah, FL) and confirmed manually using an Unopette no. 5855 dilution system (Becton-Dickinson, Rutherford, NJ) and hemocytometer. Differential counts were done on Wright's stained smears. Platelet counts were done manually.

\section{Rabbit APA}

Rabbit APA was prepared as previously described $(9,21) .60 \mathrm{ml}$ of citrated sheep blood were centrifuged at $190 \mathrm{~g}$ for $40 \mathrm{~min}$. The supernatant platelet-rich plasma was removed and centrifuged at 1,200 $g$ for $20 \mathrm{~min}$. The pellet was then suspended in $3 \mathrm{ml}$ of a solution of $0.75 \mathrm{~g} / 100 \mathrm{~cm}^{3} \mathrm{NH}_{4} \mathrm{Cl}$. The mixture was agitated, and $10 \mathrm{ml}$ of $0.9 \%$ $\mathrm{NaCl}$ and $1.0 \mathrm{ml}$ of $3.8 \mathrm{~g} / 100 \mathrm{ml}$ sodium citrate were added to the mixture. This mixture was centrifuged at $1200 \mathrm{~g}$ for $20 \mathrm{~min}$. The resulting pellet was washed in the saline/citrate solution and centrifuged at $1200 \mathrm{~g}$ for $20 \mathrm{~min}$ three additional times.

The final pellet was resuspended in $0.9 \% \mathrm{NaCl}$ and then microscopically examined for purity of its platelet content. Any observation of erythrocytes or leukocytes in the counting chamber caused rejection of the batch. Accepted batches were divided into $0.5-\mathrm{ml}$ aliquots. Each aliquot was mixed with $0.5 \mathrm{ml}$ Freund's adjuvant and injected subcutaneously into rabbits each week for 6 wk. Complete adjuvant was used for the first week only, and then incomplete adjuvant was employed for the subsequent five injections.

1 wk following the sixth injection, rabbit serum was collected and incubated at $57^{\circ} \mathrm{C}$ for $30 \mathrm{~min}$ to inactivate complement. This serum was then absorbed to sheep erythrocytes, washed in citrated saline, and stored frozen in 2-ml aliquots. Control serum was obtained from rabbits and prepared as above. The appropriate serum was thawed, diluted to $50 \mathrm{ml}$ in $0.9 \% \mathrm{NaCl}$, and filtered through a $40-\mu \mathrm{m}$ filter to prepare for infusion.

\section{Experimental protocols}

Bolus APA. The effects of APA alone were studied in five unanesthetized yearling sheep weighing between 35 and $45 \mathrm{~kg}$. All variables were followed for a minimum of $1 \mathrm{~h}$ before injecting a $0.5-\mathrm{ml}$ bolus of APA intraarterially. All variables were then followed for the ensuing $2 \mathrm{~h}$. Sodium meclofenamate powder (Warner Lambert: Parke-Davis Pharmaceutical Div., Ann Arbor, MI) was dissolved in sterile saline (10 $\mathrm{mg} / \mathrm{ml}$ ) and infused intravenously at $5 \mathrm{mg} / \mathrm{kg}$ over $0.5 \mathrm{~h}$ followed by $3 \mathrm{mg} / \mathrm{kg} \times \mathrm{h}$ for an additional $2.5 \mathrm{~h}$ via a Harvard Apparatus Co. (S. Natick, MA) constant infusion pump.

Three sheep were studied first with bolus APA alone. After 2 or 3 $d$, these three sheep were restudied after pretreatment with meclofenamate. A $0.5-\mathrm{ml}$ bolus of APA was injected after the first hour of meclofenmate infusion and the variables were followed for the ensuing $2 \mathrm{~h}$. After an additional 2-3 d, these three sheep were restudied a third time with bolus APA in the identical manner employed in the first study. Two sheep were studied first with meclofenamate and APA and then restudied $3 \mathrm{~d}$ later with APA alone.
Platelet depletion and endotoxin. Eight unanesthetized yearling sheep weighing between 35 and $45 \mathrm{~kg}$ were studied. The identical protocol was used in the control endotoxin experiments and in the platelet depletion and endotoxin experiments, except that control rabbit serum was infused in the former and APA in the latter. After a $1 \mathrm{~h}$ base line, either control serum or APA was infused into the aorta via a Harvard Apparatus continuous infusion pump. The infusion was begun at a rate of $0.04 \mathrm{ml} / \mathrm{h}$ and gradually increased to $20.7 \mathrm{ml} / \mathrm{h}$. When APA was infused in this manner, platelet depletion $(<5,000$ platelets $/ \mathrm{mm}^{3}$ ) was accomplished without as dramatic alterations in pulmonary hemodynamics, lung mechanics, and lung fluid and solute exchange as were observed following bolus APA. Once platelet counts were $<5,000$ platelets $/ \mathrm{mm}^{3}$, the infusion rate was decreased to $2.1 \mathrm{ml} /$ $h$ and maintained at this rate for the remainder of the experiment. After 4-8 $\mathrm{h}$ of continuous APA infusion, all variables had returned to within $10 \%$ of the original base-line values. In the control APA infusion experiments, the infusion was continued for the ensuing $5 \mathrm{~h}$. The APA infusion was also continued in the platelet depletion and endotoxin experiments, except endotoxin was infused in the identical dose and manner employed in the endotoxin alone experiments Escherichia coli endotoxin (Difco Laboratory lot 3123-25 prepared by the Westphal method from $E$. coli $055: \mathrm{B} 5$ ) was infused intravenously as $0.38 \pm 0.03$ $\mu \mathrm{g} / \mathrm{kg} \pm \mathrm{SE}$ over $0.5 \mathrm{~h}$. All variables were followed for the ensuing $5 \mathrm{~h}$.

Four sheep were studied first with endotoxin alone followed by the platelet depletion and endotoxin experiments and control APA infusion experiments. An additional four sheep were studied first with platelet depletion and endotoxin and control APA infusion before the endotoxin alone experiments. $3 \mathrm{~d}$ were allowed between experiments.

\section{Statistics}

The effects of APA and endotoxin over time were studied using twoway analyses of variance (22) and comparisons made between studies using the nonparametric Wilcoxon-signed rank test and paired $t$-test when appropriate (23). Statistical analyses were performed using only paired data from the same animals. $P<0.05$ was considered significant.

\section{Results}

Bolus APA. Bolus APA caused marked changes in pulmonary hemodynamics and lung mechanics. These changes are summarized in Table I. Pulmonary artery pressure, $\mathrm{P}_{\mathrm{PA}}$, increased from $21 \pm 2$ to $62 \pm 5 \mathrm{~cm} \mathrm{H}_{2} \mathrm{O} \pm \mathrm{SE}$, and PVR from $2.52 \pm 0.23$ to $6.76 \pm 0.69 \mathrm{~cm} \mathrm{H}_{2} \mathrm{O} \cdot$ liter $^{-1} \cdot \mathrm{min}^{-1} \pm \mathrm{SE}$ at $4 \mathrm{~min}$ after bolus APA. $\triangle \mathrm{AaPO}_{2}$ increased from $17 \pm 7$ to $42 \pm 16$ at $4 \mathrm{~min}$ and $39 \pm 19$ torr \pm SE at $30 \mathrm{~min}$ after bolus APA. $\mathrm{C}_{\text {dyn }}$ decreased from $0.065 \pm 0.006$ to $0.025 \pm 0.003$ at $4 \mathrm{~min}$ and $0.032 \pm 0.004$ liter/cm $\mathrm{H}_{2} \mathrm{O} \pm \mathrm{SE}$ at $30 \mathrm{~min}$ after bolus APA. $\mathrm{R}_{\mathbf{L}}$ increased from $0.40 \pm 0.11$ to $2.82 \pm 0.65$ at $4 \mathrm{~min}$ and $6.72 \pm 1.50 \mathrm{~cm}$ $\mathrm{H}_{2} \mathrm{O} \cdot$ liter $^{-1} \cdot \mathrm{s}^{-1} \pm \mathrm{SE}$ at $30 \mathrm{~min}$ after bolus APA. Leukocyte counts were unaffected by bolus APA, but platelet counts decreased from $636,000 \pm 113,000$ to $250,000 \pm 44,000$ at $4 \mathrm{~min}$ and $158,000 \pm 49,000$ cells $/ \mathrm{mm}^{3} \pm \mathrm{SE}$ at $120 \mathrm{~min}$ after bolus APA. Blood $\mathrm{TxB}_{2}$ concentrations increased from $0.122 \pm 0.017$ to $8.348 \pm 1.467 \mathrm{ng} / \mathrm{ml} \pm \mathrm{SE}$ at $15 \mathrm{~min}$ after bolus APA, while 6-keto-PGF ${ }_{1 \alpha}$ increased from $0.039 \pm 0.017$ to $0.191 \pm 0.089$ $\mathrm{ng} / \mathrm{ml} \pm \mathrm{SE}$ at $15 \mathrm{~min}$ after bolus APA.

Meclofenamate and bolus APA. Meclofenamate itself had no effect on any of the measured variables or on the de- 


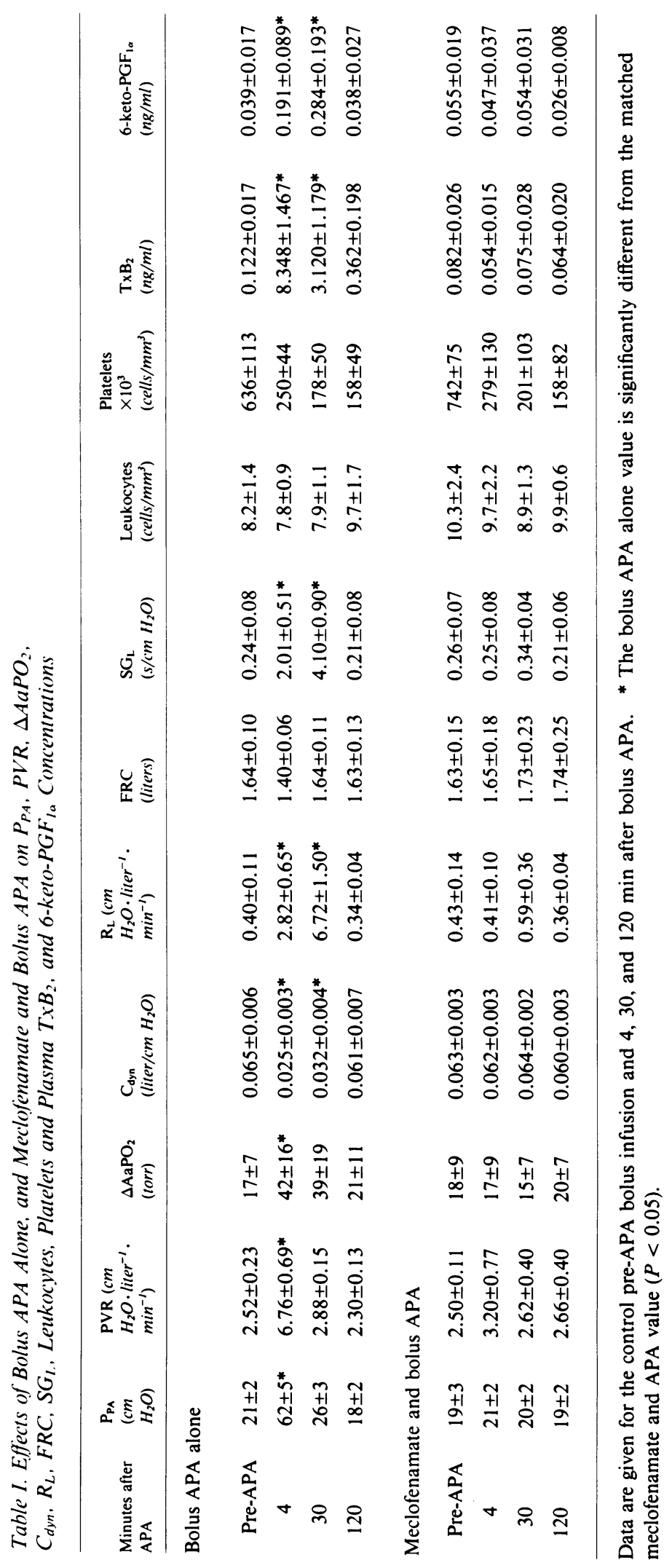


crease in platelet counts observed following bolus APA $(636,000 \pm 113,000$ to $250,000 \pm 44,000$ at $4 \mathrm{~min}$ and $158,000 \pm 49,000$ at $120 \mathrm{~min}$ after bolus APA alone and from $742,000 \pm 75,000$ to $279,000 \pm 130,000$ and $158,000 \pm 82,000$ cells $/ \mathrm{mm}^{3} \pm \mathrm{SE}$ at 4 and $120 \mathrm{~min}$ after meclofenamate and bolus APA). Meclofenamate did attenuate the increases in blood $\mathrm{TxB}_{2}$ and 6-keto-PGF $\mathrm{P}_{1 \alpha}$ as well as the alterations in $\mathrm{P}_{\mathrm{pa}}$, $P V R$, and $\triangle \mathrm{AaPO}_{2}$ at $4 \mathrm{~min}$ and the alterations in $\mathrm{C}_{\mathrm{dyn}}, \mathrm{R}_{\mathrm{L}}$, and $S_{\mathrm{L}}$ at 4 and $30 \mathrm{~min}$ after bolus APA. These results are summarized in Table $I$.

Platelet depletion and endotoxemia. In these experiments, endotoxemia caused changes in pulmonary hemodynamics, lung mechanics, lung fluid and solute exchange, and lung lymph concentrations of $\mathrm{TxB}_{2}$ and 6-keto- $\mathrm{PGF}_{1 \alpha}$ similar to those reported previously $(1,6)$. In the control endotoxin experiments, endotoxin was infused in the presence of control rabbit serum. The control rabbit serum was infused in the identical manner as the rabbit APA. In the control endotoxin experiments, platelet counts were $709,000 \pm 107,000$ cells $/ \mathrm{mm}^{3}$ before endotoxin infusion. Endotoxemia had no significant effect on platelet counts in the control endotoxin experiments or when the sheep were studied after platelet depletion. In the platelet depletion and endotoxin experiments, platelet counts were $1,875 \pm 479$ cells $/ \mathrm{mm}^{3}$ before endotoxin infusion. After 4-8 $\mathrm{h}$ of continuous APA infusion, all measured variables had returned to within $10 \%$ of the original pre-APA values. The pre-endotoxin values of all measured variables (except platelets) were not significantly different in the control endotoxin and the platelet depletion and endotoxin experiments. In the control APA infusion experiments in which APA was infused for $5 \mathrm{~h}$ after platelet depletion and no endotoxin was given, the measured variables did not change. These results are shown in Figs. 1-4.

Platelet depletion did not significantly attenuate the alterations caused by endotoxemia. Leukocytes fell to $1,240 \pm 160$ cells $/ \mathrm{mm}^{3}$ at $1 \mathrm{~h}$ after endotoxemia in the control endotoxin experiments and to $992 \pm 330$ cells $/ \mathrm{mm}^{3} \pm \mathrm{SE}$ in the platelet depletion and endotoxin experiments $(P>0.05)$ (Fig. 1). The alterations in absolute lymphocyte and granulocyte counts were similar in the two groups of experiments. $P_{P A}$ increased to $52.0 \pm 6.1 \mathrm{~cm} \mathrm{H}_{2} \mathrm{O}$ in the endotoxin control experiments and to $51.6 \pm 4.9 \mathrm{~cm} \mathrm{H}_{2} \mathrm{O} \pm \mathrm{SE}$ in the platelet depletion and endotoxin experiments at $1 \mathrm{~h}$ after endotoxemia $(P>0.05)$ (Fig. 2). PVR increased to $8.40 \pm 0.59 \mathrm{~cm} \mathrm{H}_{2} \mathrm{O} \cdot$ liter $^{-1} \cdot \mathrm{min}^{-1}$ in the endotoxin control experiments and to $10.33 \pm 1.60 \mathrm{~cm}$ $\mathrm{H}_{2} \mathrm{O} \cdot$ liter $^{-1} \cdot \mathrm{min}^{-1} \pm \mathrm{SE}$ at $1 \mathrm{~h}$ after endotoxemia in the platelet depletion and endotoxin experiments $(P>0.05)$ (Fig. 2). $\triangle \mathrm{AaPO}_{2}$ increased to $44 \pm 6$ at $1 \mathrm{~h}$ and $44 \pm 7$ at $5 \mathrm{~h}$ after endotoxemia in the control endotoxin experiments and to $50 \pm 8$ and $46 \pm 10$ torr $\pm \mathrm{SE}$ in the platelet depletion and endotoxin experiments $(P>0.05)$ (Fig. 2). $\dot{Q}_{\text {lymph }}$ increased to $9.6 \pm 1.2 \mathrm{ml} / 15 \mathrm{~min}$ at $1 \mathrm{~h}$ and to $7.2 \pm 2.2 \mathrm{ml} / 15 \mathrm{~min} \pm \mathrm{SE}$ at $5 \mathrm{~h}$ following endotoxemia in the control endotoxin experiments, and to $8.9 \pm 0.7$ at $1 \mathrm{~h}$ and $7.3 \pm 1.6 \mathrm{ml} / 15 \mathrm{~min} \pm \mathrm{SE}$ at

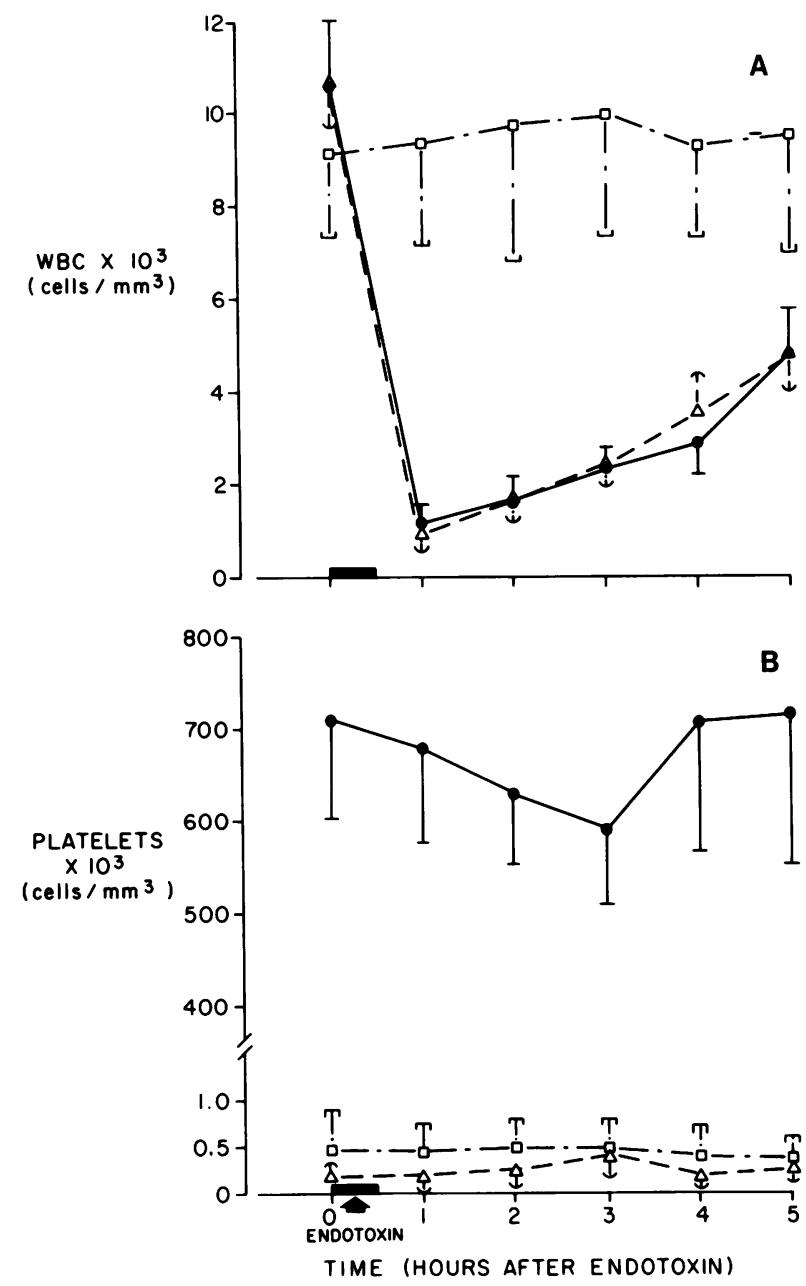

Figure 1. $(A)$ is leukocyte (WBC) count against time in hours after endotoxin while $(B)$ is platelet count against time in hours after endotoxin. Each point, except the $1 \mathrm{~h}$ point, is the mean of the preceeding $1 \mathrm{~h}$ values for the eight sheep $\pm \mathrm{SE}$. The $1-\mathrm{h}$ point is the mean of the preceding $0.5 \mathrm{~h} \pm \mathrm{SE}$ for the eight sheep studied. $(-\bullet)$, data from the control endotoxin experiments; $(--\Delta-)$, data from the platelet depletion and endotoxin experiments; $(\cdots \square \cdot-)$, data from the platelet depletion alone experiments.

$5 \mathrm{~h}$ in the platelet depletion and endotoxin experiments $(P>0.05)$ (Fig. 3). The lymph/plasma protein concentration decreased from $0.69 \pm 0.03$ to $0.56 \pm 0.04$ at $1 \mathrm{~h}$ and then increased to $0.82 \pm 0.04$ at $5 \mathrm{~h}$ following endotoxemia in the control endotoxin experiments and from $0.70 \pm 0.03$ to $0.61 \pm 0.04$ at $1 \mathrm{~h}$ and to $0.79 \pm 0.06$ at $5 \mathrm{~h}$ following endotoxemia in the platelet depletion and endotoxin experiments $(P>0.05)$ (Fig. 3). $\mathrm{C}_{\mathrm{LP}}$ increased to $5.6 \pm 1.1$ at $1 \mathrm{~h}$ and $6.1 \pm 2.1 \mathrm{ml} / 15$ $\mathrm{min} \pm \mathrm{SE}$ at $5 \mathrm{~h}$ following endotoxemia in the control endotoxin experiments and to $5.8 \pm 0.9$ at $1 \mathrm{~h}$ and $5.4 \pm 1.7 \mathrm{ml} / 15 \mathrm{~min}$ $\pm \mathrm{SE}$ at $5 \mathrm{~h}$ following endotoxemia in the platelet depletion and endotoxin experiments $(P>0.05)$. 

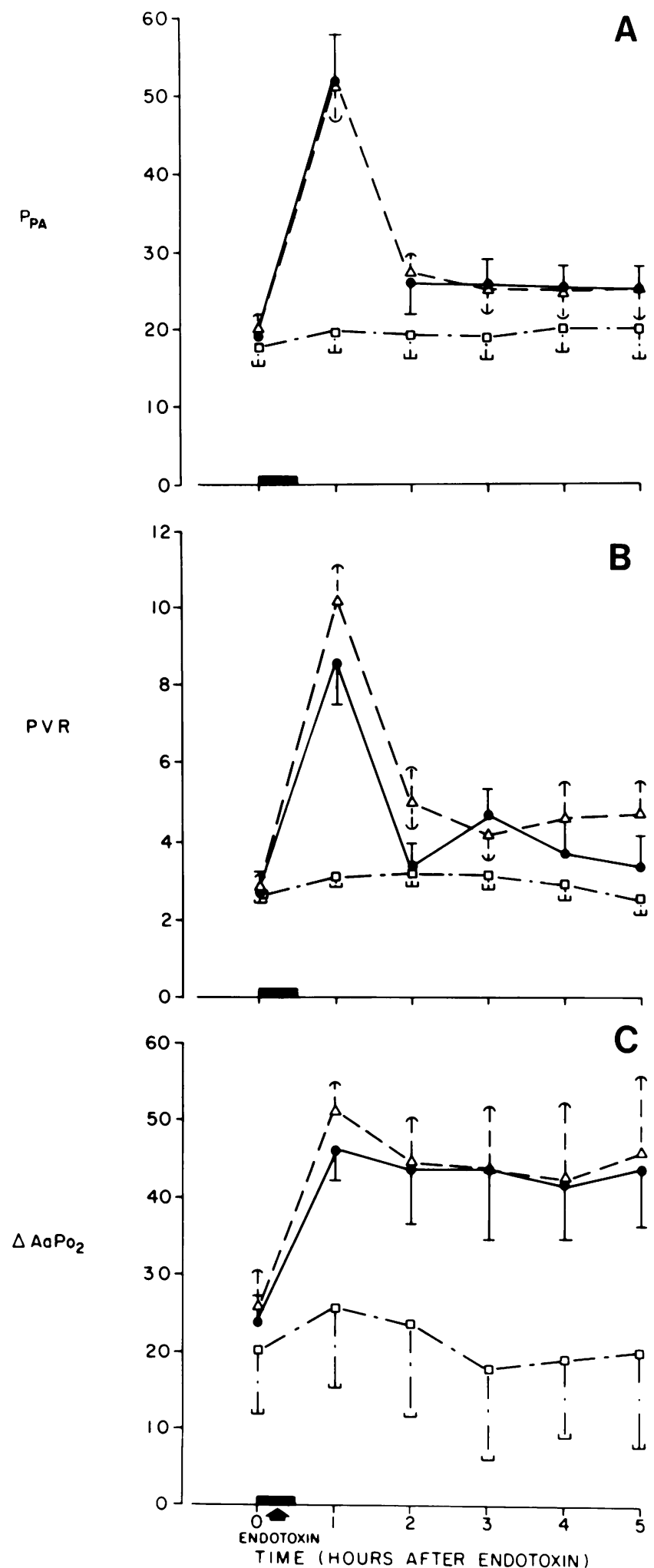

Figure 2. (A) $\mathrm{P}_{\mathrm{PA}}\left(\mathrm{cm} \mathrm{H}_{2} \mathrm{O}\right),(B) \mathrm{PVR}\left(\mathrm{cm} \mathrm{H}_{2} \mathrm{O} \cdot\right.$ liter $\left.^{-1} \cdot \mathrm{min}^{-1}\right)$, and (C) $\triangle \mathrm{AaPO}_{2}$ (torr) plotted against time in hours after endotoxin. All
At $1 \mathrm{~h}$ following endotoxemia, $\mathrm{C}_{\mathrm{dyn}}$ decreased to $0.029 \pm 0.004$ in the endotoxin control experiments and to $0.025 \pm 0.005$ liter $/ \mathrm{cm} \mathrm{H}_{2} \mathrm{O} \pm \mathrm{SE}$ in the platelet depletion and endotoxin experiments $(P>0.05)$ (Fig. 4). $\mathrm{R}_{\mathrm{L}}$ increased, at 1 $h$ after endotoxemia, to $3.45 \pm 1.06$ in the endotoxin control experiments and to $3.68 \pm 0.60 \mathrm{~cm} \mathrm{H}_{2} \mathrm{O} \cdot \operatorname{liter}^{-1} \cdot \mathrm{s}^{-1} \pm \mathrm{SE}$ in the platelet depletion and endotoxin experiments $(P>0.05)$ (Fig. 4). FRC decreased, at $1 \mathrm{~h}$ after endotoxemia, to $1.045 \pm 0.126$ in the control endotoxin experiments and to $0.979 \pm 0.146$ liters $\pm \mathrm{SE}$ in the platelet depletion and endotoxin experiments $(P>0.05)$ (Fig. 4). $\mathrm{SG}_{\mathrm{L}}$ increased to $4.11 \pm 1.70$ at $1 \mathrm{~h}$ following endotoxemia in the endotoxin control experiments and to $4.94 \pm 1.52 \mathrm{~s} / \mathrm{cm} \mathrm{H}_{2} \mathrm{O} \pm \mathrm{SE}$ in the platelet depletion and endotoxin experiments $(P>0.05)$ (Fig. 4). Lung lymph $\mathrm{TxB}_{2}$ concentrations increased from $0.340 \pm 0.289$ to $11.391 \pm 4.290$ at $1 \mathrm{~h}, 5.091 \pm 3.393$ at $2 \mathrm{~h}$, and $0.632 \pm 0.297 \mathrm{ng} / \mathrm{ml} \pm \mathrm{SE}$ at 4 $\mathrm{h}$ after endotoxemia in the control endotoxin experiments and from $0.110 \pm 0.044$ to $6.958 \pm 2.523$ at $1 \mathrm{~h}, 3.021 \pm 1.090$ at $2 \mathrm{~h}$, and $0.767 \pm 0.311$ at $4 \mathrm{~h}$ after endotoxemia in the platelet depletion and endotoxin experiments. The increase in $\mathrm{TxB}_{2}$ concentration, compared with the pre-endotoxin in controls, was significant $(P<0.05)$ in the control endotoxin at 1,2 , and $4 \mathrm{~h}$ and at 1 and $2 \mathrm{~h}$ in the platelet depletion and endotoxin experiments. No significant differences were observed at any point in time between $\mathrm{TxB}_{2}$ concentrations in lung lymph in the two groups of experiments (endotoxin compared with platelet depletion and endotoxin). Lung lymph concentrations of 6-keto-PGF ${ }_{1 \alpha}$ increased from $0.024 \pm 0.010$ to $3.512 \pm 1.925$ at $1 \mathrm{~h}, 1.251 \pm 0.635$ at $2 \mathrm{~h}$, and to $0.059 \pm 0.019$ $\mathrm{ng} / \mathrm{ml} \pm \mathrm{SE}$ at $4 \mathrm{~h}$ after endotoxemia in the control endotoxin experiments and from $0.072 \pm 0.033$ to $3.496 \pm 1.584$ at $1 \mathrm{~h}$, $1.202 \pm 0.589$ at $2 \mathrm{~h}$, and $0.235 \pm 0.166 \mathrm{ng} / \mathrm{ml} \pm \mathrm{SE}$ at $4 \mathrm{~h}$ after endotoxemia in the platelet depletion and endotoxin experiments. The increase in 6-keto-PGF ${ }_{1 \alpha}$ concentrations compared with the pre-endotoxin controls was significant in both the control endotoxin experiments and the platelet depletion and endotoxin experiments at 1 and $2 \mathrm{~h}$. No significant differences were observed between 6-keto-PGF ${ }_{1 \alpha}$ concentrations in lung lymph in the two groups of experiments (endotoxin compared with platelet depletion and endotoxin). Endotoxemia was associated with the production of moderate amounts of frothy pink secretions in the control endotoxin experiments. These secretions were markedly bloody in the platelet depletion and endotoxin experiments. All four sheep studied first in the endotoxin control experiment survived to be studied again in the platelet depletion and endotoxin experiments. Two of these sheep died within $72 \mathrm{~h}$ of the second experiment. Paired

data points, except the $1 \mathrm{~h}$ point, are the mean \pm SE of the preceding $1 \mathrm{~h}$ determinations for the eight sheep studied. The $1-\mathrm{h}$ period is the mean of the preceding $0.5 \mathrm{~h}$ determinations for the eight sheep studied. ( $\bullet-)$, data from the control endotoxin experiment; $(-\triangle--)$, data from the platelet depletion and endotoxin experiments; $(\cdots,-\cdot)$, data from the platelet depletion alone experiments. 

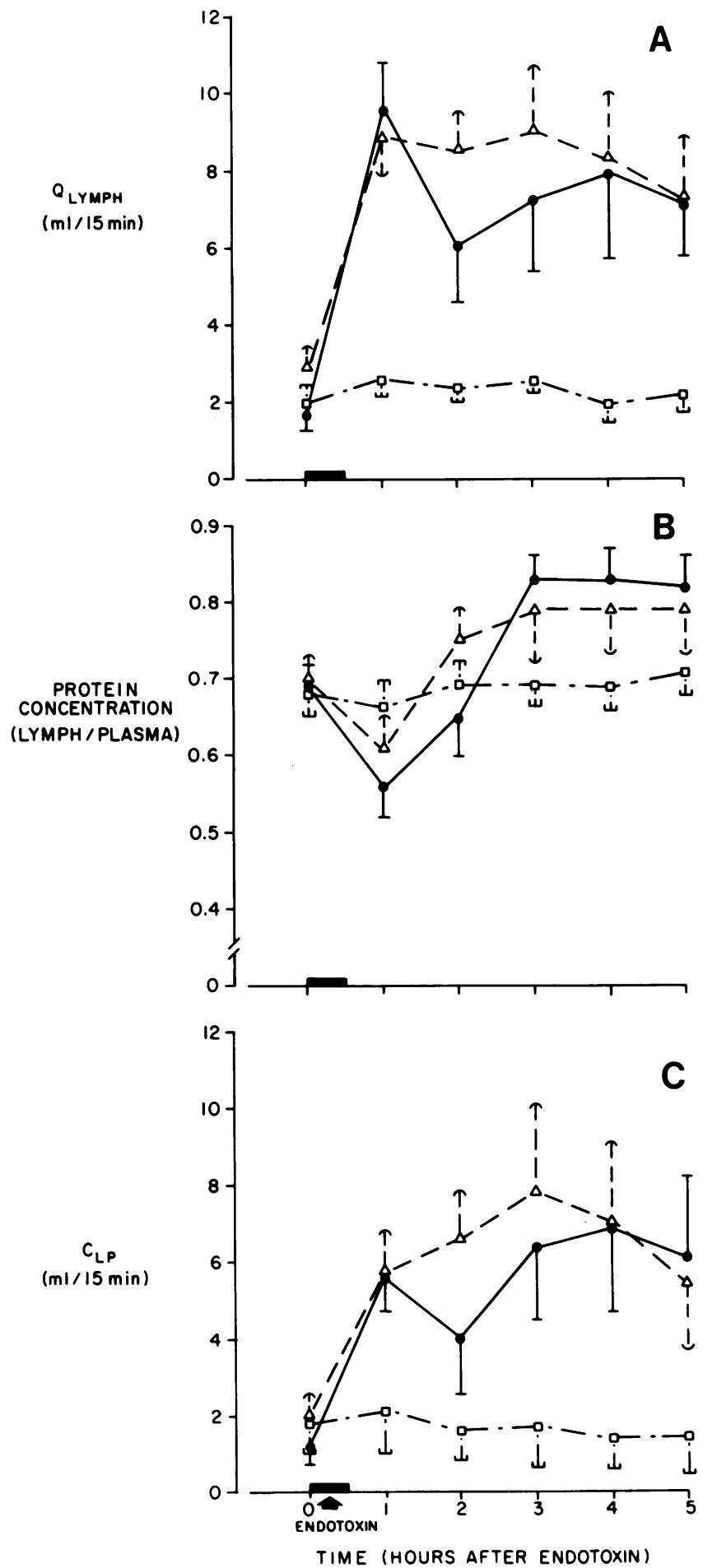

Figure 3. $(A) \dot{\mathrm{Q}}_{\text {lymph }},(B)$ the lymph/plasma protein concentration ratio, and $(C) \mathrm{C}_{\mathrm{LP}}\left(\mathrm{C}_{\mathrm{LP}}=\mathrm{lymph} / \mathrm{plasma}\right.$ protein concentration $\left.\times \dot{Q}_{\text {lymph }}\right)$. All data are plotted as the mean \pm SE for the eight sheep against time in hours after endotoxin. All but the $1 \mathrm{~h}$ point represent the mean of the determinations from the preceding $1 \mathrm{~h}$. The $1 \mathrm{~h}$ point represents the mean of the determinations from the preceding studies were available for analyses on all four sheep since none died during $5 \mathrm{~h}$ of data accumulation following endotoxin. Three of the four sheep first studied with endotoxin when platelet depleted did not survive to enter the control endotoxin experiments. Death did not occur during the $5 \mathrm{~h}$ of observation following endotoxemia. The three sheep died during the 72-h recovery period between experiments, usually within the first $24 \mathrm{~h}$ after the platelet depletion and endotoxin experiments. On gross at autopsy, the lungs appeared normal but the airways continued moderate amounts of sanguinous secretions. We speculate that death was secondary to respiratory failure in the animals studied with platelet depletion and endotoxin associated with bloody airway secretions. The loss of the three animals between experiments in the group of sheep studied first with platelet depletion and endotoxin meant that paired data was available for analysis from only one of four of these sheep.

\section{Discussion}

These experiments were designed to test the hypothesis that normal circulating platelet counts were required for the full expression of the sheep's response to endotoxemia. Endotoxemia has been employed in the sheep as an animal model of ARDS (1-7). Many interventions (cyclooxygenase inhibition $[1,15]$, corticosteroids [4], and granulocyte depletion [5, 6]) have been shown to alter one or more aspect of the sheep's response to endotoxemia. These studies suggest a possible role of cyclooxygenase products of arachidonate metabolism in the pathogenesis of the early pulmonary hypertension and altered lung mechanics observed following endotoxemia $(1,15)$. Platelets are a potentially rich source of cyclooxygenase products, especially thromboxanes, which may mediate these alterations (7-11). Therefore, it was possible that platelet depletion would alter the sheep's response to endotoxemia:

It was necessary, for these experiments, to first develop methods of depleting the sheep's platelets. Ideally, platelet depletion itself would not alter the base line values of the different variables measured. Rabbit APA were used to deplete the sheep of platelets. It was found that bolus injections of APA caused marked alterations in pulmonary hemodynamics and lung mechanics similar to those observed following endotoxemia (Table I and Figs. 2 and 4). Since the cyclooxygenase inhibiting agent, meclofenamate, inhibits the early alterations observed following endotoxemia $(1,15)$, the effects of meclofenamate on the sheep's response to bolus APA were also studied. Meclofenamate inhibited all but the decrease in platelet counts observed following APA administration. These results suggest that if platelets are the source of the cyclooxygenase products which cause the changes in pulmonary hemodynamics

0.5 h. (- - ), data from the control endotoxin experiments; $(-\Delta--)$, data from the platelet depletion and endotoxin experiments; $(\cdots \square \cdots)$, data from the platelet depletion alone experiments. 

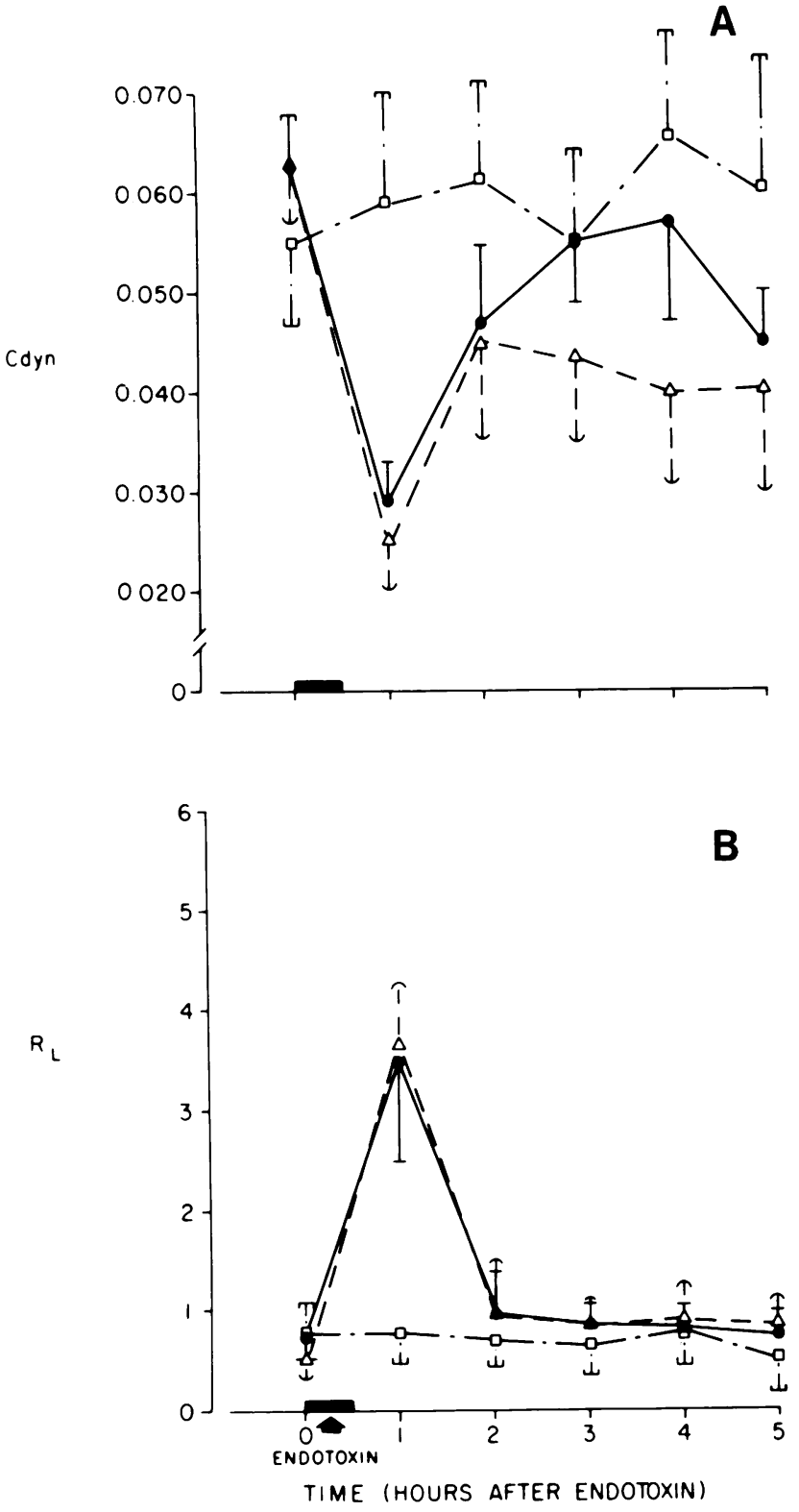

Figure 4. (A) $\mathrm{C}_{\text {dyn }}$ (liter/cm $\left.\mathrm{H}_{2} \mathrm{O}\right),(B) \mathrm{R}_{\mathrm{L}}\left(\mathrm{cm} \mathrm{H}_{2} \mathrm{O}\right.$.

liter $\left.^{-1} \cdot s^{-1}\right),(C)$ FRC (liters), and $(D) \mathrm{SG}_{\mathrm{L}}\left(\mathrm{s} / \mathrm{cm} \mathrm{H}_{2} \mathrm{O}\right)$. All data are the mean \pm SE plotted against time in hours after endotoxemia. All data points, except the $1 \mathrm{~h}$ point, represent the mean values over the preceding $1 \mathrm{~h}$ of observation for the eight sheep studied. The $1 \mathrm{~h}$

and lung mechanics after bolus APA, these released mediators are not themselves necessary for the antigen-induced removal of platelets from the circulation. It is possible that these nonmonoclonal antibodies $(9,21)$ stimulate other cells than platelets, such as mast cells or leukocytes (24), to release mediators which in turn cause the alterations in pulmonary hemodynamics and lung mechanics. Rabbit serum alone does not cause alterations in any of the variables measured. The
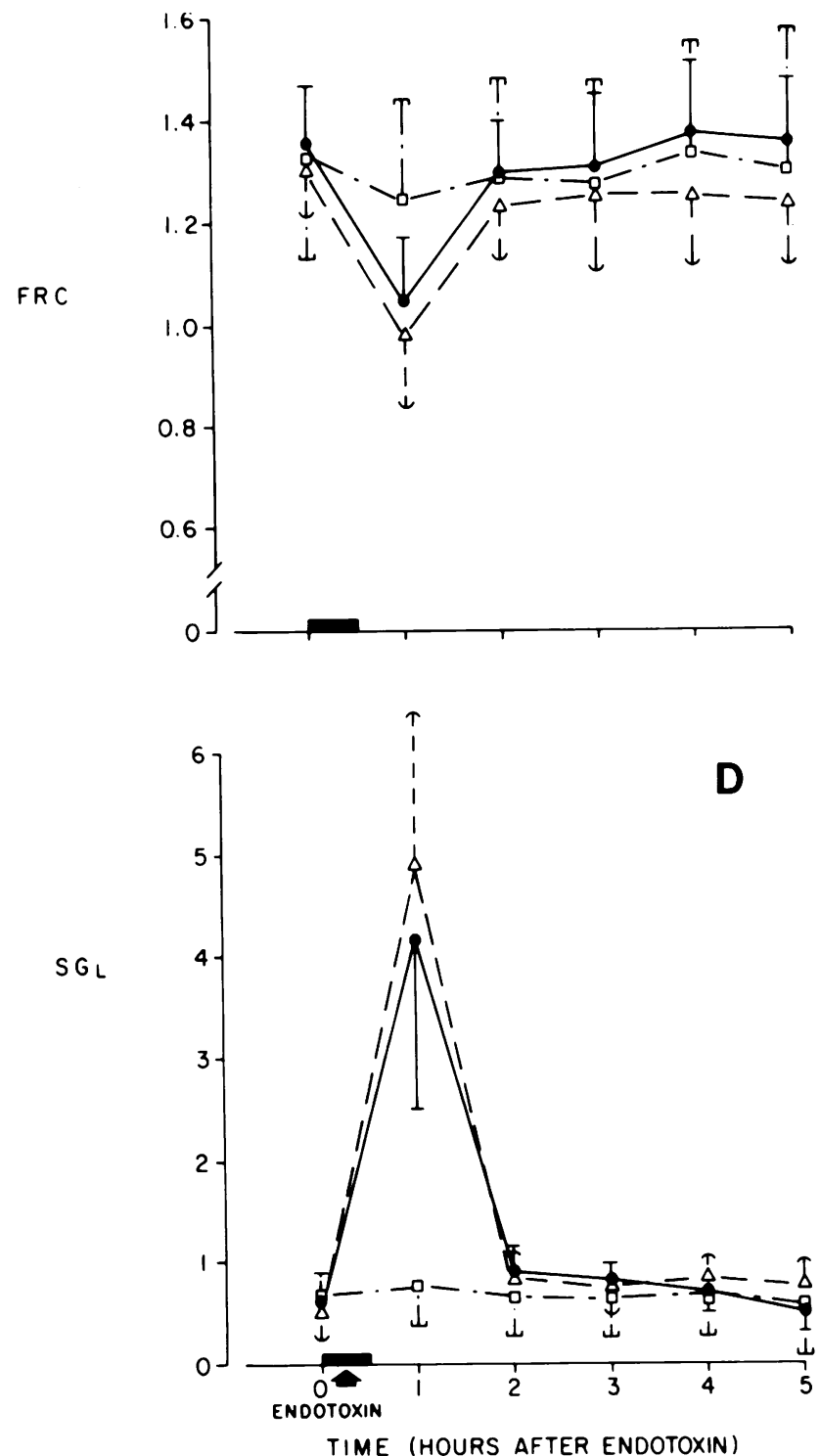

point represents the mean value from the preceding $0.5 \mathrm{~h}$ for the eight sheep studied. (-•-), data from the control endotoxin experiments; $(--\Delta--)$, data from the platelet depletion and endotoxin experiments; $(-\cdot-\square-\cdot-)$, data from the platelet depletion alone experiments.

studies with bolus APA help to define certain restrictions to experimental design with these antibodies. Repetitive doses of APA over many days results in a smaller and smaller response. It was found that up to three doses of bolus APA could be given within $1 \mathrm{wk}$ with fairly reproducible responses. Since tachyphylaxis may still occur, it is necessary, as was done in these studies, to alter the order of experimentation so as to avoid systematic bias. 
It was possible to deplete the sheep of platelets with a continuous infusion of APA over 4-8 $\mathrm{h}$ and to have all measured variables, except platelet counts, return to base line. The APA can then continue to be infused during the period of observation following endotoxemia. Control experiments in which only APA was infused for an additional $5 \mathrm{~h}$ demonstrated no further alterations in any of the measured variables (Figs. 1 to 4). These methods, though cumbersome, do allow for the study of platelet depletion on the sheep's response to endotoxemia.

Platelet depletion with APA did not attenuate the sheep's response to endotoxemia. There was no significant attenuation, by platelet depletion, of the alterations in pulmonary hemodynamics, lung mechanics, and lung fluid and solute exchange caused by endotoxemia (Figs. 1-4). Platelet depletion increased the likelihood of death following endotoxemia. The normal increase in airway secretions observed following endotoxemia became grossly bloody in the platelet-depleted sheep. Though all sheep survived for the $5 \mathrm{~h}$ of data acquisition following endotoxemia in the platelet depletion and endotoxin experiments, five of eight sheep died within $72 \mathrm{~h}$ of these experiments. All sheep survived the endotoxin control experiments. Certainly, normal circulating platelet counts are not necessary for the full expression of the sheep's response to endotoxemia.

These results are consistent with other observations with endotoxemia in the sheep and with results with glass bead microembolism (11) and complement activation (8). Endotoxemia did not cause significant alterations in platelet counts (Fig. 1), and histologically, platelets are not prominent in the pathologic changes observed following endotoxemia in the sheep (25). Both lung lymph concentrations of $\mathrm{TxB}_{2}$ and 6-keto-PGF $F_{1 \alpha}$ increased significantly in the platelet depletion and endotoxin experiments, suggesting that endotoxemia causes the release of thromboxanes and prostacyclin from a source other than circulating platelets. These results are consistent with those observed with zymosan-activated complement in sheep (8). Although platelets may be a rich source of mediators (7-11) and may still be pathologically important in ARDS (715), normal circulating platelet counts are not necessary for the full expression of the sheep's response to endotoxemia.

In the unanesthetized sheep, endotoxemia has proven to be a valuable model to elucidate the mechanisms of endotoxininduced lung injury (1-7). How relevant results with platelet depletion and endotoxemia in the current series of experiments to other animal models and to ARDS in man? Sheep platelets have similarities and differences with platelets from other species and man (26-30). Sheep platelets are poorly responsive to exogenous thromboxane, arachidonates, or epinephrine. Sheep platelets aggregate with collagen, thrombin, ADP, and serotonin, and do produce serotonin and thromboxane when stimulated. Sheep platelets only produce $17.5 \%$ of the thromboxane produced by human platelets when stimulated by the same dose of collagen (30). Dog platelets are intermediate between sheep and man in their ability to produce thromboxane when stimulated (30). These differences may account for platelet depletion attenuating the pulmonary hypertension observed in endotoxin shock in dogs (14) and the absence of any attenuation of the pulmonary hypertension following endotoxemia in the sheep ARDS model. It is apparent from this study, as well as from complement activation (8), that other sources exist in sheep for thromboxane production than simply circulating platelets. It is also possible that cyclooxygenase products of arachidonate other than thromboxane cause the early pulmonary hypertension observed following endotoxemia and complement activation in sheep $(1,8,15)$. Platelet depletion does, for example, attenuate by $>50 \%$ the increase in peak plasma $\mathrm{TxB}_{2}$ concentrations observed following cardiopulmonary bypass in sheep but does not attenuate the pulmonary hypertension (31). It is possible that platelets are more important in ARDS in man than in the lung injury caused by endotoxemia in sheep. These studies are important though since they illustrate that platelets are not necessary for the lung injury or the production of cyclooxygenase products in this model of lung injury.

In summary, bolus infusion of APA cause marked alterations in pulmonary hemodynamics and lung mechanics as well as depletion in circulating platelet counts. The alterations in pulmonary hemodynamics and lung mechanics, but not the drop in circulating platelet counts, were inhibited by the cyclooxygenase inhibiting agent, meclofenamate. It was possible, with the continuous infusion of APA, to deplete platelets without altering base-line values of the measured variables. Platelet depletion did not attenuate the sheep's response to endotoxemia or the normal increase in cyclooxygenase products observed in lung lymph following endotoxemia. Normal circulating platelet counts are not necessary for the full expression of the sheep's response to endotoxemia.

\section{Acknowledgments}

The authors would like to thank Gayle A. King for her fine technical assistance.

This work was supported by National Heart, Lung, and Blood Institute grants nos. HL 19153 (Specialized Centers of Research in Pulmonary Vascular Diseases) and HL 27274 and the Parker B. Francis Foundation.

\section{References}

1. Snapper, J. R., A. A. Hutchison, M. L. Ogletree, and K. L. Brigham. 1983. Effects of cyclooxygenase inhibitors on the alterations in lung mechanics caused by endotoxemia in the unanesthetized sheep. J. Clin. Invest. 72:63-76.

2. Esbenshade, A. M., J. H. Newman, P. M. Lams, H. Jolles, and K. L. Brigham. 1982. Respiratory failure after endotoxin infusion in sheep: lung mechanics and fluid balance. J. Appl. Physiol.: Respir. Environ. Exercise Physiol. 53(4):967-976.

3. Brigham, K. L., R. E. Bowers, and J. Haynes. 1979. Increased sheep vascular permeability caused by $E$. coli endotoxin. Circ. Res. 45:292-297. 
4. Brigham, K. L., R. E. Bowers, and C. R. McKeen. 1981. Methylprednisolone prevention of increased lung vascular permeability following endotoxemia in sheep. J. Clin. Invest. 67:1103-1110.

5. Heflin, A. C., and K. L. Brigham. 1981. Prevention by granulocyte depletion of increased lung vascular permeability of sheep lung following endotoxemia. J. Clin. Invest. 68:1253-1260.

6. Hinson, J. M., Jr., A. A. Hutchison, M. L. Ogletree, K. L. Brigham, and J. R. Snapper. 1983. Effect of granulocyte depletion on altered lung mechanics after endotoxemia in sheep. J. Appl. Physiol.: Resp. Environ. Exercise Physiol. 55(1):92-99.

7. Brigham, K. L., J. H. Newman, J. R. Snapper, and M. L. Ogletree. 1982. Metabolites of arachidonate acid in the pathophysiology of the pulmonary circulation. In Prostaglandins and the Cardiovascular System. J. Oates, editor. Raven Press, New York. 355-368.

8. McDonald, J. W. D., M. Ali, E. Morgan, E. R. Townsend, and J. D. Cooper. 1983. Thromboxane synthesis by causes other than platelets in association with complement-induced pulmonary leukostasis and pulmonary hypertension in sheep. Circ. Res. 52:1-6.

9. Evensen, S. A., and R. F. Elgjo. 1972. Antibody-induced platelet injury: its potency as a trigger of intravascular clotting. Scand. $J$. Haemat. 9:61-72.

10. Vaage, J. 1982. Intravascular platelet aggregation and pulmonary injury. Ann. NY Acad. Sci. 384:301-318.

11. Binder, A. S., W. Kageler, A. Perel, M. Flick, and N. C. Staub. 1980. Effect of platelet depletion on lung vascular permeability after microemboli in sheep. J. Appl. Physiol.: Respirat. Environ. Exercise Physiol. 48(3):414-420.

12. Martin, B. A., R. Dahlby, I. Nicholls, and J. C. Hogg. 1981. Platelet sequestration in lung with hemorrhagic shock and reinfusion in dogs. J. Appl. Physiol.: Respirat. Environ. Exercise Physiol. 50(6): 1306-1312.

13. Hechtman, H. B., E. A. Lonergan, H. P. B. Staunton, R. C. Dennis, and D. Shepro. 1978. Pulmonary entrapment of platelets during acute respiratory failure. Surgery. 83(3):277-283.

14. Bredenberg, C. E., G. A. Taylor, and W. R. Webb. 1980. The effect of thrombocytopenia on the pulmonary and systemic hemodynamics of canine endotoxin shock. Surgery. 87:59-68.

15. Ogletree, M. L., and K. L. Brigham. 1982. Effects of cyclooxygenase inhibitors on pulmonary vascular responses to endotoxin in unanesthetized sheep. Prostaglandins Leukotrienes Med. 8:489-502.

16. Staub, N., R. Bland, K. Brigham, R. Demling, J. Erdmann, and W. Woolverton. 1975. Preparation of chronic lung lymph fistulas in sheep. J. Surg. Res. 19:315-320.

17. Gunther, R., and R. Demling. 1981. Effect of diaphragmatic lymph contamination on caudal mediastinal node, $\mathrm{CMN}$, lymph flow in unanesthetized sheep. Physiologist. 24:53.

18. Von Neergaard, K., and K. Wirz. 1927. Die Messung der
Stromungswiderstande in den Atemwegen des Menschen, Insbesondere bei Asthma und Emphysem. Z. Kin. Med. 105:51-82.

19. DuBois, A. B., S. Y. Bothelho, G. N. Bedell, R. Marshall, and J. H. Comroe. 1956. A rapid plethysmographic method measuring thoracic gas volume: a comparison with nitrogen washout method for measuring functional residual capacity in normal subjects. J. Clin. Med. 35:322-327.

20. Failing, J., M. Buckley, and D. Zak. 1960. Automatic determination of serum proteins. Am. J. Clin. Pathol. 33:83-88.

21. Corash, L., H. Tan, and H. R. Gralnick. 1977. Heterogeneity of human whole blood platelet subpopulations. 1. Relationship between buoyant density, cell volume, and ultrastructure. Blood. 49(1):71-87.

22. Snedecor, G. W., and W. G. Cochran. 1967. Statistical Methods Applied to Experiments in Agriculture and Biology. Iowa State University Press, Ames, IO. Sixth ed. 95-101.

23. Mosteller, F., and R. E. K. Rouke. 1973. Sturdy Statistics: Nonparametrics and Order Statistics. Addison-Wesley Publishing Co., Reading, MA. 89-102.

24. Kovacs, I. B., and J. P. Caen. 1979. Increased interactions of vascular endothelium and leukocytes after administration of antiplatelet serum: role in the developing vascular defect. J. Clin. Path. 32:445449.

25. Meyrick, B., and K. L. Brigham. 1983. Acute effects of E. coli endotoxin on the pulmonary microcirculation of anesthetized sheep: structure-function relationships. Lab. Invest. 48(4):458-470.

26. Dodds, W. J. 1978. Platelet function in animals: species specificities. In Platelets: A Multidisciplinary Approach. G. de Gaetano and S. Garattini, editors. Raven Press, New York. 45-59.

27. Addonizio, V. P., Jr., L. H. Edmunds, Jr., and R. W. Colman. 1978. The function of monkey (M. mulatta) platelets compared to platelets of pig, sheep and man. J. Lab. Clin. Med. 91:989-997.

28. Meyers, K. M., J. B. Katz, R. M. Clemmons, J. B. Smith, and H. Holmsen. 1980. An evaluation of the arachidonate pathway of platelets from companion and food-producing animals, mink and man. Thrombosis Res. 20:13-24.

29. Burke, S. E., A. M. Leffer, K. C. Nicholaou, G. M. Smith, and J. B. Smith. 1983. Responsiveness of platelets and coronary arteries from different species to synthetic thromboxane and prostaglandin endoperoxide analogues. Br. J. Pharmacol. 78:287-292.

30. Leach, C. M., and G. D. Thorburn. 1982. A comparative study of collagen induced thromboxane release from platelets of different species: implications for human atherosclerosis models. Prostaglandins. 24:47-59.

31. Wonders, T. R., J. R. Southmayd, A. H. Schuette, P. D. Huttenmeier, D. Kong, W. D. Watkins, A. Carvalho, and W. M. Zapol. 1981. Reduced plasma thromboxane elevation during partial cardiopulmonary bypass in thrombocytopenic sheep. Trans. Am. Soc. Artif. Intern. Organs. 27:276-279. 